\title{
Evaluation of antifibrotic effects of coffee and cocoa extracts in rats with thioacetamide-induced fibrosis
}

\author{
Grażyna Budryn ${ }^{1} \cdot$ Dorota Żyżelewicz $^{1} \cdot$ Vyacheslav Buko $^{2} \cdot$ Oxana Lukivskaya $^{2} \cdot$ Elena Naruta $^{2}$.

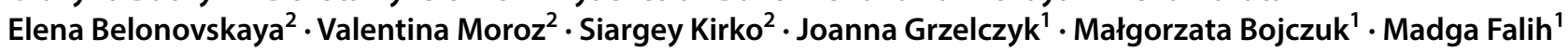

Received: 16 April 2018 / Revised: 19 June 2018 / Accepted: 30 June 2018 / Published online: 31 July 2018

(c) The Author(s) 2018

\begin{abstract}
Epidemiological data demonstrate an inverse relationship between consumption of coffee as well as other beverages containing methylxanthines and liver fibrosis. The mechanism may include the action of not only methylxanthines but also phenolic compounds. Regarding coffee and cocoa, the levels of phenolic compounds strongly depend on the form of beans, i.e., raw (green) vs. roasted. The aim of this study was to evaluate the antifibrotic effects of coffee and cocoa extracts (both from green and roasted beans) on liver fibrosis progression in thioacetamide (TAA)-treated rats. Among the investigated extracts, only green coffee extract developed a more pronounced antifibrotic effect, partially preventing TAA-induced liver fibrosis, confirmed by the significant decrease of both total and relative hydroxyproline contents in the liver.
\end{abstract}

Keywords Coffee $\cdot$ Cocoa $\cdot$ Polyphenols $\cdot$ Methylxanthines $\cdot$ Liver fibrosis

\section{Introduction}

Liver injuries affect a large part of the human population. One of the most frequently observed pathological states of the liver is fibrosis. In liver fibrosis, tumor growth factor $\beta$ (TGF- $\beta$ ) is a cytokine secreted in large amounts. One of the most significant effects of TGF- $\beta$ secretion is the activation of hepatic stellate cells (HSC). In fibrotic liver, HSC

Electronic supplementary material The online version of this article (https://doi.org/10.1007/s00217-018-3119-z) contains supplementary material, which is available to authorized users.

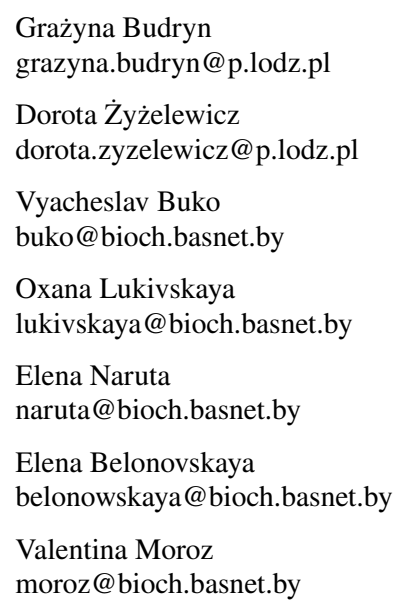

are differentiated and the secretion of extracellular matrix proteins is clearly enhanced, a process commonly known as HSC activation [1]. Hepatocytes are replaced by abundant extracellular matrixes consisting mainly of collagen types I-III-IV, fibronectin, elastin, laminin, and proteoglycans. Because inflammation is a key process contributing to the pathogenesis of liver fibrosis, inflammation reduction, and immune response is an important way of treating liver fibrosis. Some plants produce compounds that inhibit inflammation. Among the phytochemicals exhibiting an inhibitory effect on liver fibrosis, caffeine and its derivatives

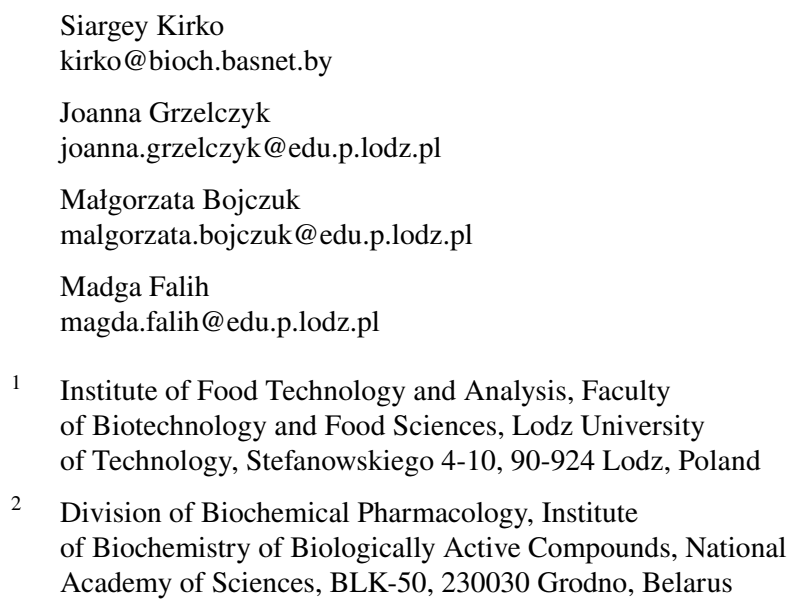
of Biotechnology and Food Sciences, Lodz University of Technology, Stefanowskiego 4-10, 90-924 Lodz, Poland

2 Division of Biochemical Pharmacology, Institute of Biochemistry of Biologically Active Compounds, National Academy of Sciences, BLK-50, 230030 Grodno, Belarus 
are mentioned. Chan et al. [2] attributed this effect to the antagonistic activity of caffeine to the adenosine receptor (A2aAR) [3]. Gressner et al. [4] demonstrated that caffeine and paraxanthine inhibit TGF- $\beta$-induced collagen tissue growth factor (CTGF) expression.

It was also found that coffee consumption was inversely correlated with serum alanine aminotransferase (ALT) and gamma-glutamyltransferase (GGT) levels, both of which are markers of liver injury and fibrosis [5, 6]. High coffee consumption ( $>2$ cups per day) was associated with a lower risk of elevated ALT and a lower risk of chronic liver disease. A large cohort study of patients with alcoholic and nonalcoholic cirrhosis demonstrated a strong inverse relationship between coffee drinking ( $>4$ cups a day) and elevated serum enzyme levels [7]. On the other hand, several studies have shown that decaffeinated coffee also has a protective effect on liver fibrosis, suggesting that the mechanism of action may not depend solely on caffeine [8]. Among the compounds in coffee that may have anti-inflammatory effects are polyphenols that are represented by chlorogenic acids (CGA) that can prevent liver damage by regulating glutathione and thioredoxin antioxidant systems [9-12]. Antioxidant and reducing liver injury properties show other polyphenols, such as flavonols, contained in cocoa [13, 14]. All the previous studies concerned coffee or cocoa only after roasting. It is known, however, that roasting causes dramatic changes in the composition of polyphenols by reactions with amino acids, polymerization, and degradation to compounds of lower molecular weight. Therefore, in recent years, there has been a steady trend of consumption of both products without roasting. So far, the impact of raw coffee and cocoa on liver fibrosis has not been studied. The aim of the study was to compare the effects of coffee and cocoa before and after roasting on the inhibition of induced liver fibrosis.

\section{Materials and methods}

\section{Chemicals and reagents}

Analytical-grade hexane was purchased from Poch (Gliwice, Poland); HPLC-grade formic acid and acetonitrile from Fluka (St. Louis, MO, USA); 5-caffeoylquinic acid (99\%), caffeic acid (99\%), ferulic acid (99\%), 3,4-dicaffeoylquinic acid (98\%), benzoic acid (99\%), catechin ( $\geq 99 \%)$, epicatechin ( $\geq 98 \%$ ), epigallocatechin $(\geq 90 \%)$, procyanidin B2 $(\geq 90 \%)$, procyanidin $\mathrm{C} 1(\geq 75 \%)$, quercetin $(\geq 95 \%)$, quercetin-3-O-glucoside ( $\geq 98 \%$ ), quercetin-3-O-galactoside $(\geq 97 \%)$, and quercetin-3- $O$-arabinoside ( $\geq 95 \%)$ from Sigma-Aldrich (St. Louis, MO, USA); 3-caffeoylqunic acid (99\%), 4-caffeoylqunic acid (99\%), 3,5-dicaffeoylquinic acid (99\%), and 4,5-dicaffeoylquinic acid (99\%) from PhytoLab (Vestenbergsgreuth, Germany); and nylon filters from
Chromacol (Herts, UK). Ultrapure water (resistivity, 18.2 $\mathrm{M} \Omega \mathrm{cm}$ ) was obtained from a Millipore Milli-Q Plus purification system (Bedford, MA, USA). Kits for serum marker enzyme activities were from LaChema (Brno, Czech Republic); kits for TNF- $\alpha$, TGF- $\beta$, IL- 6 , and IFN- $\gamma$ determination from R\&D Systems GmbH (Wiesbaden, Germany); kits for hyaluronic acid, laminin, type I collagen measurements, and assay kits for measurement of hyaluronic acid, laminin, and type I collagen from Wuhan USCN Sciences Co., Ltd. (Wuhan, China).

\section{Coffee and cocoa beans roasting}

Green Robusta coffee beans (Coffea canephora L.) harvested in Brazil in 2016, dry hulled, were purchased from Bero Polska (Gdynia, Poland). Raw Forastero variety cocoa beans (Theobroma cacao L.) harvested in Peru in 2016 with $5.8 \%$ water content were purchased from Barry Callebaut (Lodz, Poland). Roasting of coffee and cocoa beans was conducted in a convective automatic CBR-101 roaster with a load capacity of $200 \mathrm{~g}$ (Gene Café, Gyeonggi-do, Korea). The temperature of coffee roasting was $230{ }^{\circ} \mathrm{C}$. The time was adjusted to achieve a weight loss of $17 \%$ and amounted $12 \mathrm{~min}$. Cocoa beans were roasted for $35 \mathrm{~min}$ at $135^{\circ} \mathrm{C}$. The water content of $2.0 \%$ in the roasted cocoa beans was the endpoint of the roasting [15].

\section{Preparing coffee and cocoa extracts}

The coffee extracts were obtained using $400 \mathrm{~g}$ of ground coffee beans and 1:5.75 (w/w) ratio of ground coffee to water. The suspension was boiled in a pressure vessel (PS-5682 Vienna, Austria) at $110{ }^{\circ} \mathrm{C}$ for $10 \mathrm{~min}$, cooled in a water bath to $40^{\circ} \mathrm{C}$, and filtered using a KNF $18035.3 \mathrm{~N}$ vacuum pump (Neuberger, NJ, USA) [16]. The cocoa extracts were obtained using ground cocoa beans and water in 1:3 (w/w) ratio, respectively. The suspensions in Erlenmeyer flasks were placed in a SV1422 Memmert water bath with shaker (Schwabach, Germany). Extraction of bioactive compounds was carried out at $60^{\circ} \mathrm{C}$ for $30 \mathrm{~min}$ and the suspensions were filtered as above. The extracts were freeze-dried in a DELTA 1-24LSC Christ freeze drier (Osterode am Harz, Germany) and stored at $-25^{\circ} \mathrm{C}$.

\section{Polyphenol and methylxanthine analysis by the UHPLC-DAD-UHR-Q-TOF-ESI-MS/MS}

Chromatographic analysis was carried out using UHPLC ${ }^{+}$ Ultimate 3000 system with an auto sampler, an DAD detector from Dionex (Sunnyvale, CA, USA), and an ultrahigh resolution hybrid quadrupole/time of-flight mass spectrometer (UHR-Q-TOF-MS/MS, Bruker Daltonics GmbH, Bremen, Germany) using ESI source. An Accucore ${ }^{\mathrm{TM}} \mathrm{C} 18$ 
column from Thermo Scientific (Palo Alto, CA, USA) was used. The mobile phase consisted of water/formic acid (99.9:0.1, v/v) (solvent A) and acetonitrile/water/formic acid (80:19.98:0.02, v/v/v) (solvent B). Flavan-3-ols, procyanidins, gallic acid, and methylxanthines were quantified at $280 \mathrm{~nm}$, while chlorogenic acids at 325 and flavonols at $365 \mathrm{~nm}$. The quantification was performed using the internal standard (benzoic acid) and external standard (corresponding standard except feruloylquinic acids). All feruloylquinic acids were quantified as 5-caffeoylquinic acid equivalents. MS/MS spectra were obtained in collision-induced dissociation (CID) mode. Full-scan mass spectra were acquired in the negative ion mode for flavan-3-ols, flavonols, and CGA, and positive ion mode for anthocyanins and methylxanthines. Identification and peak assignment were based on the comparison of their retention times, UV and full-scan mass spectra, and MS/MS fragmentation patterns with those of authentic standards, as well as the bibliographic references [17].

\section{Animal experiment design}

Male Wistar rats weighing 230-250 g (60 animals) handled at temperature-controlled conditions had free access to water and standard AIN-G93G diet developed by the American Institute of Nutrition. Experimental liver fibrosis was induced by intraperitoneal (i.p.) TAA treatment $(200 \mathrm{mg} / \mathrm{kg}$ b.w.) two times a week for 10 weeks. After the first 4 weeks of the TAA treatment, the rats were administered the test compounds. The control group and one of the TAA-treated groups, which was used as an experimental control for the tested substances, received water by gavage. The test compounds were dissolved in water and administered daily (100 mg/kg b.w.), intragastrically (i.g.) by oral gavage during the last 6 weeks of the trial. Each group consisted of ten animals. Rats were killed via terminal bleeding under pentobarbital anaesthesia (40 mg/kg, i.p.). The care, use, and procedures performed on these rats were approved by the Ethics Committee of the National Academy of Sciences, Belarus (Protocol no. 10/17 of 20.02.2017), and complied with the European Convention for the Protection of Vertebrate Animals Used for Experimental and Other Scientific Purposes and NIH guide for the care and use of laboratory animals (NIH publication no. 80-23; revised 1978).

\section{Analysis of liver histopathology}

Liver specimens were fixed in $10 \%$ formalin and embedded in paraffin. 5- $\mu \mathrm{m}$-thick sections were processed routinely for hematoxylin and eosin (H\&E), and Sirius red staining. The slides stained with Azan-Mallory were used for morphometric analysis to determine the percentage of liver tissue affected by fibrosis using a computer-assisted image analyzer (BIOSCAN,
Minsk, Belarus). Results from 15 random fields per slide (fibrosis index) were calculated as a ratio of the Azan-Mallory-positive area to the total area examined and expressed as a relative square of connective tissue (\% to the total slide square) [18]. The relative square of connective (fibrotic) tissue in the liver was evaluated by computer-assisted morphometry and liver hydroxyproline content (relative and total). Analyzing inflammatory infiltration, we registered inflammatory foci consisting of three and more cells in ten fields of view from each slide.

\section{Biochemical assays}

Blood was drawn from all animals at the moment of death and the contents of serum alanine aminotransferase (ALT), aspartate aminotransferase (AST), and alkaline phosphatase (ALP) were determined. No significant changes of these parameters were obtained. Specimens of the liver were immediately snapfrozen for hydroxyproline determination. Hydroxyproline content was determined by a modification of Jamall's method [19]. Liver specimens ( $250 \mathrm{mg}$ each) were homogenized in buffer and hydrolyzed in $5 \mathrm{~mL}$ of $6 \mathrm{~N} \mathrm{HCl}$ at $110{ }^{\circ} \mathrm{C}$ for $16 \mathrm{~h}$. After hydrolysis, the samples were analyzed for hydroxyproline content biochemically and quantified spectrophotometrically at $558 \mathrm{~nm}$.

\section{Serum cytokines and fibrosis markers}

Cytokines TNF- $\alpha$ and IL- 6 characterized the anti-inflammatory effect of the investigated compounds, whereas changes in TGF- $\beta$ content, the main profibrogenic cytokine, reflect the inhibition of fibrogenic processes by the extracts. IFN- $\gamma$ is a pluripotent cytokine developing clear antifibrotic properties. Hyaluronic acid, laminin, and type I collagen are serum markers which reflect the values of components of extracellular matrix (fibrotic tissue). Levels of all the above parameters were measured using the enzyme-linked immunosorbent assay method with the appropriate commercial kits.

\section{Statistical analysis}

All the data were expressed as mean \pm SEM between groups and compared by the one-way analysis of variance (ANOVA) with the Tukey's multiple comparison post hoc test using Graph Pad Prism 5 (GraphPad Software, Inc., USA). The level of significance was considered at $P<0.05$. 


\section{Results}

\section{Liver histology}

The rats are administrated coffee and cocoa extracts of the composition are given in Table 1. Histological observations of liver sections from control animals showed normal hepatic architecture with sinusoidal spaces, central vein, and radiating hepatic cords (Fig. 1a, g). Rats treated for 10 weeks with TAA showed severe fibrosis characterized by an obvious increase in extracellular matrix collagen deposition, a formation of porto-portal bridging fibrotic septum throughout the liver parenchyma, and distorted tissue architecture (Fig. 1h). H\&E staining revealed that
TAA treatment caused fibrotic scars with portal and lobular inflammatory cell infiltration and periportal necrosis (Fig. 1b). Liver sections from fibrotic rats administered with green coffee extract showed reduction in fibrosis compared with liver sections of rats treated with only TAA (Fig. 1k). A reduction of inflammatory signs was observed in groups treated with raw cocoa and green coffee extracts (Fig. 1c-e; Table 2). Other extracts did not show significant improvements of liver histology. Morphometric evaluation of Azan-Mallory stained slides from the TAA-treated group demonstrated a dramatic increase of collagen deposition (more than 7.5 -fold, $P<0.0001$ ) where all the investigated extracts did not statistically significantly affect this parameter (Table 2).

Table 1 Concentration of polyphenols and methylxanthines in green (raw) and roasted coffee and cocoa extracts

\begin{tabular}{|c|c|c|c|c|c|}
\hline Compound (g/100 g) & Green coffee & Roasted coffee & Compound (g/100 g) & Raw cocoa & Roasted cocoa \\
\hline 3-O-Caffeoylquinic acid & $5.43 \pm 0.09^{\mathrm{b}}$ & $0.84 \pm 0.03^{\mathrm{a}}$ & Catechin & $0.02 \pm 0.00^{\mathrm{b}}$ & $0.05 \pm 0.00^{\mathrm{a}}$ \\
\hline 5-O-Caffeoylquinic acid & $10.92 \pm 0.83^{\mathrm{b}}$ & $1.68 \pm 0.05^{\mathrm{a}}$ & Epicatechin & $0.87 \pm 0.02^{\mathrm{b}}$ & $0.64 \pm 0.05^{\mathrm{a}}$ \\
\hline 4-O-Caffeoylquinic acid & $6.66 \pm 0.11^{\mathrm{b}}$ & $0.99 \pm 0.02^{\mathrm{a}}$ & Epigallocatechin & $0.14 \pm 0.01^{\mathrm{b}}$ & $0.03 \pm 0.00^{\mathrm{a}}$ \\
\hline 3-O-Feruloylquinic acid & $0.81 \pm 0.05^{\mathrm{b}}$ & $0.24 \pm 0.01^{\mathrm{a}}$ & Procyanidin B2 & $0.76 \pm 0.02^{\mathrm{b}}$ & $0.72 \pm 0.02^{\mathrm{a}}$ \\
\hline 5-O-Feruloylquinic acid & $3.09 \pm 0.18^{b}$ & $0.54 \pm 0.01^{\mathrm{a}}$ & Procyanidin $\mathrm{C} 1$ & $0.24 \pm 0.02^{\mathrm{b}}$ & $0.14 \pm 0.01^{\mathrm{a}}$ \\
\hline 4-O-Feruloylquinic acid & $1.08 \pm 0.05^{\mathrm{b}}$ & $0.18 \pm 0.01^{\mathrm{a}}$ & Other procyanidins & $1.14 \pm 0.05^{\mathrm{b}}$ & $1.04 \pm 0.04^{\mathrm{a}}$ \\
\hline 3,4-Di- $O$-caffeoylquinic acid & $1.38 \pm 0.04^{b}$ & $0.09 \pm 0.00^{\mathrm{a}}$ & Quercetin 3-O-glucoside & $0.03 \pm 0.01^{\mathrm{b}}$ & $0.03 \pm 0.01^{\mathrm{a}}$ \\
\hline 3,5-Di- $O$-caffeoylquinic acid & $2.43 \pm 0.07^{\mathrm{b}}$ & $0.06 \pm 0.00^{\mathrm{a}}$ & Quercetin 3-O-arabinoside & $0.03 \pm 0.00 \mathrm{a}^{\mathrm{a}}$ & $0.03 \pm 0.00^{\mathrm{a}}$ \\
\hline \multirow[t]{2}{*}{ 4,5-Di- $O$-caffeoylquinic acid } & $0.06 \pm 0.01^{\mathrm{b}}$ & $0.12 \pm 0.00^{\mathrm{a}}$ & Quercetin 3-O-galactoside & $0.01 \pm 0.00^{\mathrm{a}}$ & $0.01 \pm 0.00^{\mathrm{a}}$ \\
\hline & & & Gallic acid & nd & $0.19 \pm 0.02^{\mathrm{a}}$ \\
\hline Total chlorogenic acids & $31.86 \pm 1.54^{\mathrm{b}}$ & $4.74 \pm 0.13^{\mathrm{a}}$ & Total phenolic substances & $3.24 \pm 0.11^{\mathrm{b}}$ & $2.88 \pm 0.15^{\mathrm{a}}$ \\
\hline Caffeine & $6.08 \pm 0.15^{\mathrm{a}}$ & $6.16 \pm 0.21^{b}$ & Theobromine and caffeine & $6.26 \pm 0.18^{\mathrm{a}}$ & $6.34 \pm 0.09^{\mathrm{a}}$ \\
\hline
\end{tabular}

Different letters in one row for the same product correspond to significant differences $(P<0.05)$


Fig. 1 Microphotographs of representative liver sections. Upper panel: hematoxylin and eosin staining. Sections are shown at original magnification $\times 200$. a Control rats; b TAA-treated group. The TAA treatment showed the development of extensive fibrosis. Rats with liver fibrosis treated with the extracts: c raw cocoa; $\mathbf{d}$ roasted cocoa; e green coffee; $\mathbf{f}$ roasted coffee. Inflammatory foci, necrotic area, and scattered lymphocytic infiltration in the TAA-treated group. Beneficial effect of green coffee extract (e) is mostly pronounced. Lower


panel: Azan-Mallory staining. Sections are shown at original magnification $\times 400$. $\mathbf{g}$ Control rats; $\mathbf{h}$ TAA-treated group. The TAA treatment showed the development of extensive fibrosis. Rats with liver fibrosis treated with the extracts: $\mathbf{i}$ raw cocoa; $\mathbf{j}$ roasted cocoa; $\mathbf{k}$ green coffee; $\mathbf{l}$ roasted coffee. The treatment with extract from green coffee (k) showed a significant attenuation of fibrotic changes. The treatment with other extract did not affect histological pictures of liver fibrosis 
Table 2 Parameters characterizing liver fibrosis influenced by coffee and cocoa extracts

\begin{tabular}{|c|c|c|c|c|c|c|}
\hline Values & Control & TAA & TAA + green coffee & TAA + roasted coffee & TAA + raw cocoa & TAA + roasted cocoa \\
\hline $\begin{array}{l}\text { Relative square of the } \\
\text { connective tissue, } \% \text { to } \\
\text { total slide square }\end{array}$ & $1.20 \pm 0.12$ & $9.20 \pm 1.10^{\mathrm{a}}$ & $7.16 \pm 1.21^{\mathrm{a}}$ & $11.57 \pm 1.70^{\mathrm{a}}$ & $7.62 \pm 1.02^{\mathrm{a}}$ & $9.06 \pm 0.99^{\mathrm{a}}$ \\
\hline $\begin{array}{l}\text { Relative hydroxyproline, } \\
\mu \mathrm{g} / \mathrm{g} \text { liver tissue }\end{array}$ & $550.43 \pm 0.48$ & $1267 \pm 29.44^{\mathrm{a}}$ & $1129 \pm 32.71^{\mathrm{a}, \mathrm{b}}$ & $1294 \pm 38.31^{\mathrm{a}, \mathrm{c}}$ & $1359 \pm 50.92^{\mathrm{a}}$ & $1261 \pm 42.24^{\mathrm{a}}$ \\
\hline $\begin{array}{l}\text { Total hydroxyproline, } \\
\text { mg/whole liver }\end{array}$ & $6.51 \pm 0.410$ & $18.16 \pm 0.856^{\mathrm{a}}$ & $14.97 \pm 0.626^{\mathrm{a}, \mathrm{b}}$ & $16.96 \pm 0.679^{\mathrm{a}, \mathrm{c}}$ & $18.87 \pm 0.976^{\mathrm{a}}$ & $18.33 \pm 1.34^{\mathrm{a}}$ \\
\hline
\end{tabular}

${ }^{\text {a }}$ Significantly $(P<0.05)$ as compared to the control group

${ }^{\mathrm{b}}$ Significantly to the TAA group

${ }^{\mathrm{c}}$ Significantly between the raw and roasted groups

\section{Macromorphological measurements}

We found no changes of body, liver, and spleen weights in all the experimental groups after 10 weeks of the TAA treatment (data not shown). Subsequently, the liver and spleen indices were calculated as the percentage of the body weight. The liver index was decreased in all the TAA-treated groups, where the treatment with all the extracts studied did not affect this ratio, whereas the spleen index did not change in groups treated with TAA and all the investigated extracts.

\section{Liver hydroxyproline}

Hydroxyproline is an amino acid which occurs in all collagens and comprised about $12-13 \%$ of total amino acid pool in these proteins. Therefore, hydroxyproline is a representative for liver tissue collagen, the main component of extracellular matrix. Liver hydroxyproline serves as a gold standard for an evaluation of fibrosis [20]. It is an extremely stable parameter and an even slight but a significant decrease in it suggests potential antifibrotic activity of compounds studied. After 10 weeks of TAA treatment, we showed dramatically increased liver contents of hydroxyproline, both relative (2.3-fold) and total (2.8-fold) (Table 2). Among the used extracts, only green coffee administration significantly lowered these parameters.

\section{Serum cytokines}

As shown in Figs. 2, 3, 4, and 5, and Supplementary Table 1, the levels of serum TGF- $\beta$, TNF- $\alpha$, and IL- 6 in the TAAtreated group were significantly higher than those in the normal control group. Upregulation of TGF- $\beta$ was markedly inhibited by all the investigated extracts, whereas only both coffee extracts significantly decreased TNF- $\alpha$ and IL-6 contents in serum. The serum level of antifibrotic cytokine IFN- $\gamma$ was markedly decreased in the TAA-treated animals as compared to the control group. The treatment of fibrotic rats with both cocoa extracts elevated the value of IFN- $\gamma$

Fig. 2 TGF- $\beta$ contents influ-

TGF $\beta$

enced by coffee and cocoa

extracts

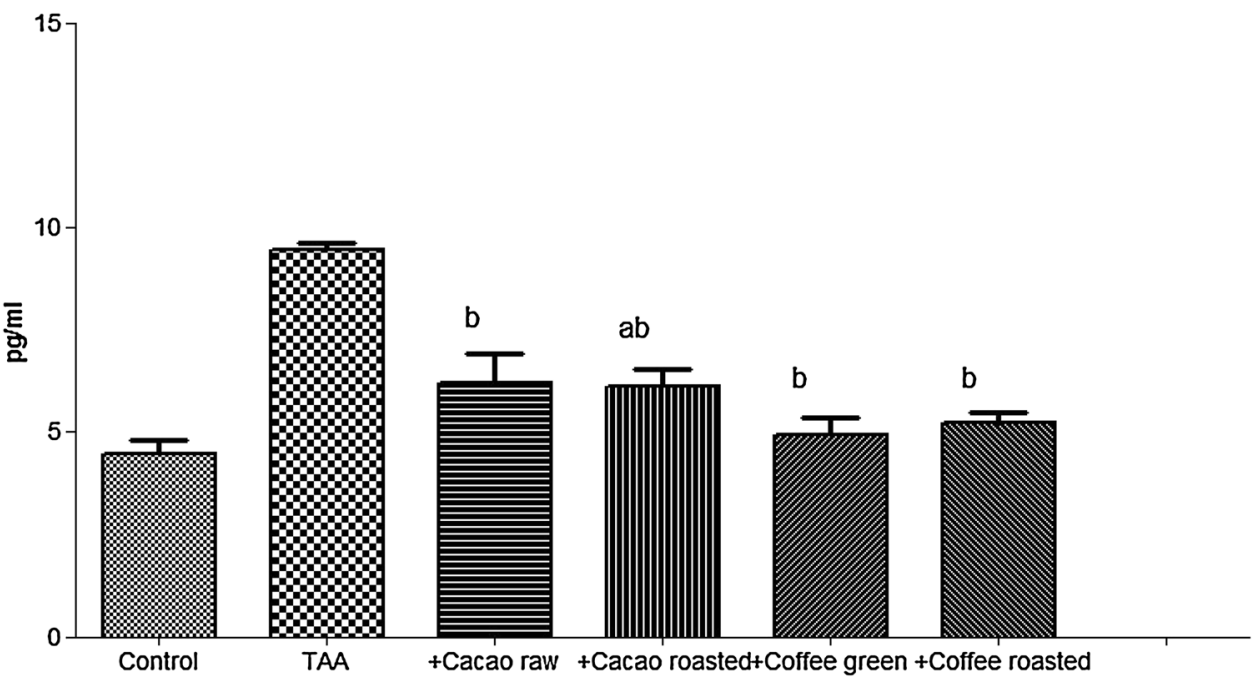


Fig. 3 TNF- $\alpha$ contents influenced by coffee and cocoa extracts
TNF $\alpha$

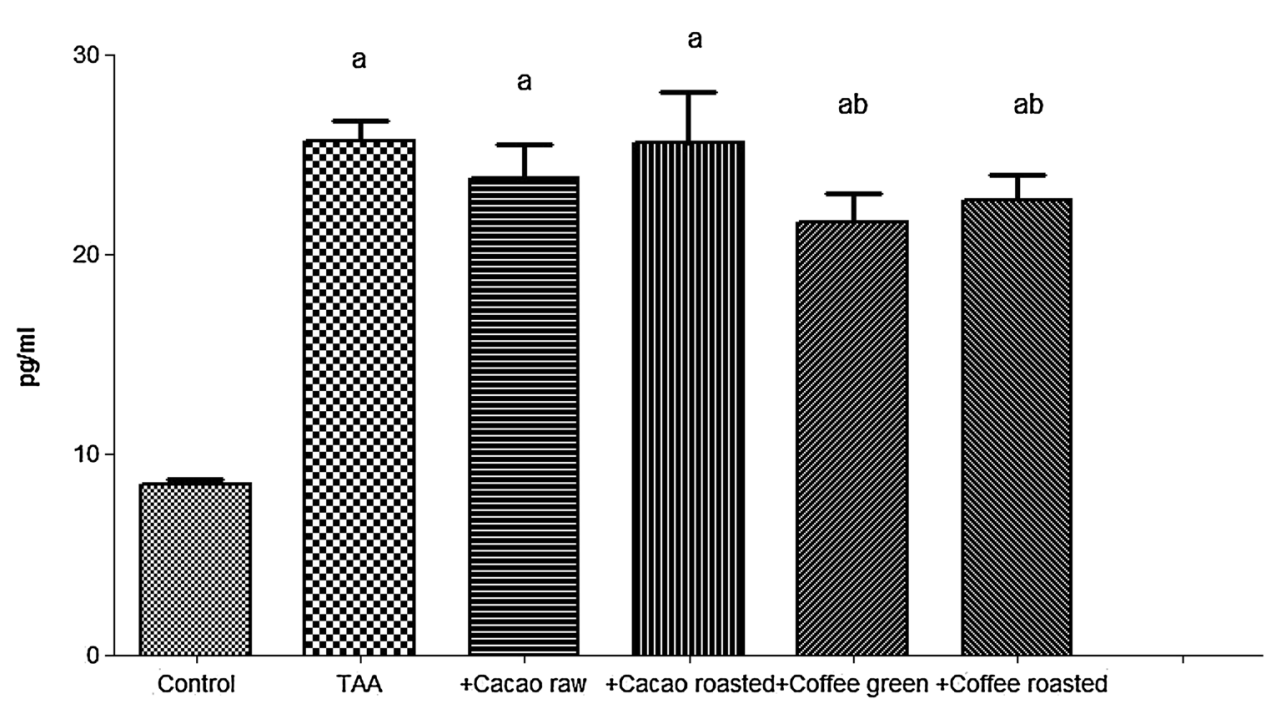

IL-6

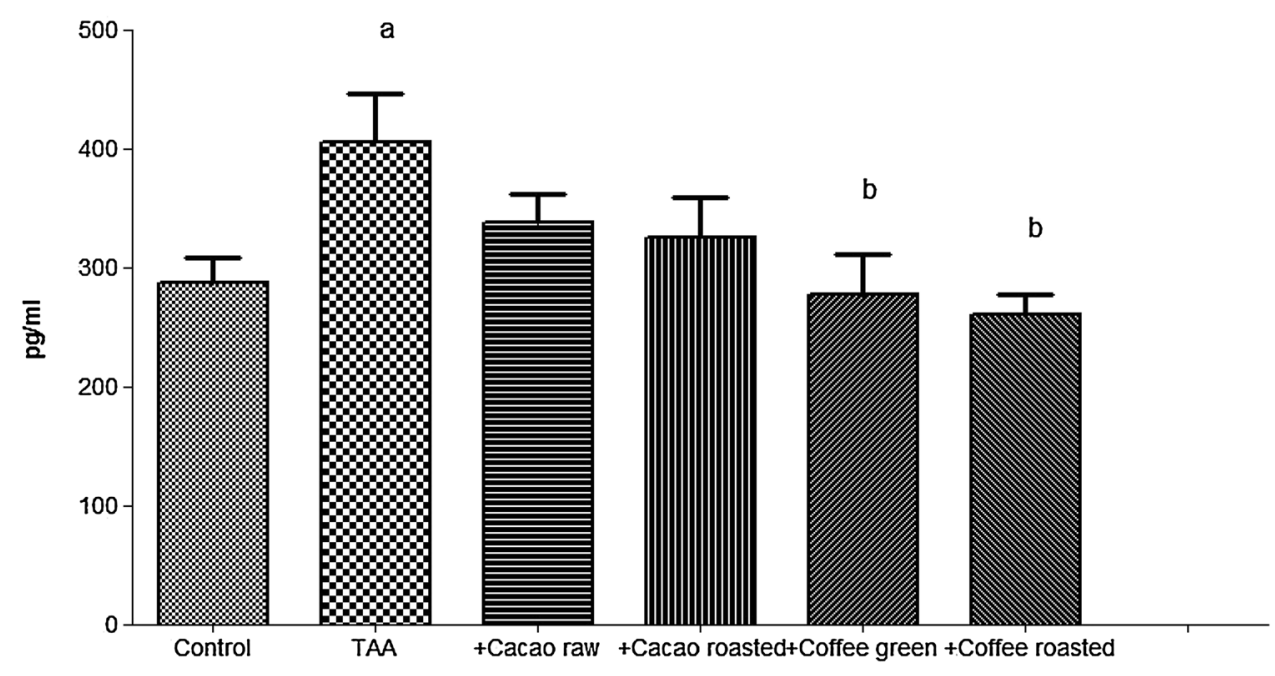

significantly higher than those of the control group, whereas neither raw nor roasted cocoa affected this parameter.

\section{Serum fibrosis markers}

Serum hyaluronic acid, laminin, and collagens are important biomarkers of hepatic fibrogenesis used to diagnose liver fibrosis severity both in clinical and under experimental conditions. These parameters are increased with the progression of liver fibrosis. In this study, we showed a significant increase of hyaluronic acid (1.8-fold), laminin (2.7-fold), and type I collagen (4.3-fold) in serum of TAAtreated rats in comparison to the control group (Table 3 ). The administration of both coffee extracts markedly decreased hyaluronic acid and laminin contents, whereas collagen I content was lowered only in the green coffee group.

\section{Serum enzyme activity}

Serum AST, ALT, and ALP activities are reliable markers of liver damage. When damage of liver parenchymal cell occurs, these enzymes are released into blood stream from the tissue. TAA administration to normal rats significantly elevated the level of serum ALT (1.5-fold), AST (1.9-fold), and ALP (3.3-fold) compared with control rats (Table 3). At the same time, none of the studied substances affected the activity of these enzymes. 
Fig. 5 INF- $\gamma$ contents influenced by coffee and cocoa extracts
INF $\gamma$

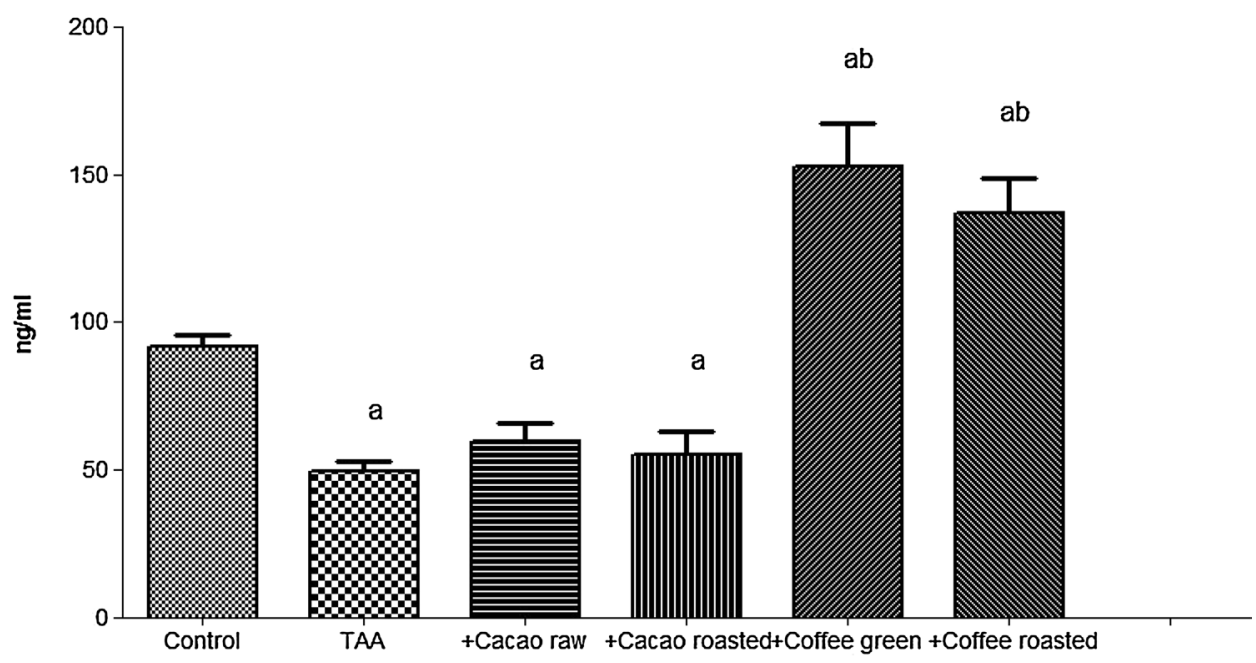

Table 3 Fibrosis markers influenced by coffee and cocoa extracts

\begin{tabular}{lllllll}
\hline Values & Control & TAA & TAA+green coffee & TAA+roasted coffee & TAA+raw cocoa & TAA+roasted cocoa \\
\hline Hyaluronic acid (ng/mL) & $37.15 \pm 1.03$ & $68.67 \pm 6.97^{\mathrm{a}}$ & $39.89 \pm 5.83^{\mathrm{b}}$ & $42.36 \pm 2.21^{\mathrm{b}}$ & $59.49 \pm 6.72^{\mathrm{a}}$ & $63.16 \pm 3.83^{\mathrm{a}}$ \\
Laminin (pg/mL) & $24.36 \pm 0.75$ & $65.83 \pm 3.96^{\mathrm{a}}$ & $46.53 \pm 3.77^{\mathrm{ab}}$ & $49.46 \pm 2.95^{\mathrm{ab}}$ & $59.21 \pm 3.94^{\mathrm{a}}$ & $57.13 \pm 2.24^{\mathrm{a}}$ \\
Collagen I (pg/mL) & $29.38 \pm 3.88$ & $125.1 \pm 7.24^{\mathrm{a}}$ & $103.9 \pm 4.18^{\mathrm{ab}}$ & $113.8 \pm 4.03^{\mathrm{ac}}$ & $107.30 \pm 5.27^{\mathrm{a}}$ & $122.2 \pm 2.96^{\mathrm{ac}}$ \\
ALT (U/L) & $60.81 \pm 2.747$ & $91.23 \pm 5.239^{\mathrm{a}}$ & $78.94 \pm 5.850^{\mathrm{a}}$ & $88.47 \pm 5.643^{\mathrm{a}}$ & $81.45 \pm 4.528^{\mathrm{a}}$ & $97.69 \pm 4.827^{\mathrm{ac}}$ \\
AST (U/L) & $74.11 \pm 3.312$ & $139.5 \pm 7.014^{\mathrm{a}}$ & $138.3 \pm 9.751^{\mathrm{a}}$ & $136.5 \pm 14.330^{\mathrm{a}}$ & $118.4 \pm 10.170^{\mathrm{a}}$ & $145.1 \pm 8.709^{\mathrm{ac}}$ \\
ALP (U/L) & $155.3 \pm 19.41$ & $507.1 \pm 46.82^{\mathrm{a}}$ & $568.5 \pm 50.56^{\mathrm{a}}$ & $570.6 \pm 46.32^{\mathrm{a}}$ & $493.8 \pm 47.36^{\mathrm{a}}$ & $615.0 \pm 41.46^{\mathrm{ac}}$ \\
\hline
\end{tabular}



${ }^{\mathrm{b}}$ Significantly to the TAA group

${ }^{\mathrm{c}}$ Significantly between the raw and roasted groups

\section{Discussion}

Liver fibrosis is an excessive deposition of extracellular matrix represented mainly as collagens. Fibrosis results from chronic liver injury and is associated with inflammatory diseases, such as viral hepatitis, alcoholic and nonalcoholic steatohepatitis, or autoimmune liver diseases [21]. TAA-induced liver fibrosis has been shown to resemble human pathology, and is widely used for studying of mechanisms of liver fibrosis and testing of antifibrotic and regulating agents [22]. The present study demonstrated that TAA at a dose of $200 \mathrm{mg} / \mathrm{kg}$ body weight twice per week over 10 weeks induced liver fibrosis with many histopathological and biochemical alterations in rats. TAA intoxication caused massive deposition of extracellular matrix in the liver which was confirmed by the significant gain in the relative weights of body liver, the dramatic increase in the relative area of connective tissue, and total and relative contents of hydroxyproline in the liver. Moreover, the increased serum content of hyaluronic acid, laminin, and type I collagen also confirmed the development of liver fibrosis in rats. The obtained results showed an elevation in the levels of serum ALT, AST, and ALP that suggested the impairment of liver function which accompanied liver fibrosis. The TAA treatment showed pro-inflammatory responses as evidenced by a significant amount of the number of inflammatory foci in the liver. Furthermore, we demonstrated a significant elevation of pro-inflammatory cytokines, TNF- $\alpha$ and IL-6, in serum, that indicate amplified inflammatory responses in TAAtreated rats. Pro-inflammatory cytokines promote fibrosis in the liver through inhibition of fibrolysis and stimulation of HSC proliferation [23]. In addition, pro-inflammatory signaling pathways, mediated by TNF- $\alpha$ and interleukins, interact with TGF- $\beta$, main profibrotic cytokine, which activates fibrogenesis in the liver. As we demonstrated in this study, the treatment of rats with TAA markedly elevated serum content of TGF- $\beta$. At the same time, serum level of cytokine IFN- $\gamma$, with antifibrotic properties via inhibiting HSC activation decreased in TAA-treated rats [24, 25]. 
The obtained results showed that, among four tested extracts, only green coffee extract caused the histopathological and biochemical alterations in TAA-treated animals. This extract showed clear antifibrotic effects decreasing contents of total and relative hydroxyproline in the liver, normalizing serum level of main profibrogenic cytokine TGF- $\beta$, and lowering contents of serum fibrosis markers: hyaluronic acid, laminin, and collagen I. The anti-inflammatory effect of the green coffee extract was characterized by the significant lowering of inflammatory foci number in the liver and the decrease of pro-inflammatory cytokines: TNF- $\alpha$ and IL- 6 levels in serum. This indicated the effectiveness of this extract in the prevention of TAA-induced liver fibrosis. The roasted coffee extract exerted moderate antifibrotic potential. It decreased serum TGF- $\beta$, TNF- $\alpha$, and IL- 6 contents, and two serum fibrosis markers: hyaluronic acid and laminin levels. However, no effects of raw and roasted cocoa extracts rich in flavan3-ols and theobromine were found in TAA-treated rats excepting serum IFN- $\gamma$ which was elevated over the control value after treatments with both cocoa extracts. None of the studied extracts exerted hepatoprotective effect as was suggested by the lack of changes of activities of enzymatic markers in serum. The concentrations of caffeine in green coffee and roasted coffee extracts were comparable and, therefore, we assume that the antifibrotic effect of the green coffee extract is dependent on chlorogenic acids, the content of which in roasted coffee decreased after the roasting at more than sixfold. The study in which the effects of conventional caffeinated coffee and decaffeinated coffee in rats treated with thioacetamide were compared demonstrated that both types of coffee similarly reduce liver fibrosis [26]. The literature data suggest that chlorogenic acids prevents $\mathrm{CCl}_{4}$-induced liver fibrosis and inflammation via the suppression of oxidative stress and the inhibition of TLR4/MyD88/NF-кB signaling pathway in the liver [27]. On the other hand, we cannot exclude an additional impact of caffeine on the antifibrotic action of green coffee extract. Caffeine inhibits HSC activation and angiogenesis which precede a deposition of extracellular matrix fibers in the liver [28]. However, in our earlier studies, we analyzed the impact of extracts of coffee and cocoa free of methylxanthines (caffeine and theobromine) on the antioxidant status of blood and organs of rats fed a pro-oxidative diet. The level of substances reacting with thiobarbituric acid, which was an indicator of the presence of oxidized fatty acids, was analyzed. The study showed that the extracts of raw coffee and cocoa improved the antioxidant status of the liver in the pro-oxidative diet [15, 29]. These results were consistent with the results obtained by Salomone et al. [30], who showed that, in rats, decaffeinated coffee induced the expression of master regulators of redox status. Additional studies aimed at establishing the impact of particular coffee bioactive components on the prevention of liver fibrosis must be undertaken.

\section{Conclusions}

In conclusion, among the investigated substances, only green coffee extract developed more pronounced antifibrotic and anti-inflammatory effects, partially preventing TAA-induced liver fibrosis. The antifibrotic effect of roasted coffee extract has been expressed much more weakly than that of green coffee extract. Cocoa extracts (raw and roasted) showed neither antifibrotic nor anti-inflammatory activities in the presented model of experimental liver fibrosis induced by TAA. The green coffee extract was characterized by the highest concentration of polyphenols compering to the other extracts and the role of the chlorogenic acids might be crucial in inhibition of liver fibrosis.

Acknowledgements Authors are grateful for the financial support provided by the National Research and Development Center (Project no. POIG.02.01.00-10-171/09).

\section{Compliance with ethical standards}

Conflict of interest The authors declare that there is no conflict of interests regarding the publication of this article. All the authors reviewed the paper and approved the final version.

Compliance with ethics requirements All applicable international, national, and/or institutional guidelines for the care and use of animals were followed. All procedures performed in studies involving animals were in accordance with the ethical standards of the institution or practice at which the studies were conducted. This article does not contain any studies with human.

Open Access This article is distributed under the terms of the Creative Commons Attribution 4.0 International License (http://creativeco mmons.org/licenses/by/4.0/), which permits unrestricted use, distribution, and reproduction in any medium, provided you give appropriate credit to the original author(s) and the source, provide a link to the Creative Commons license, and indicate if changes were made.

\section{References}

1. Duval F, Moreno-Cuevas JE, González-Garza MT, MaldonadoBernal C, Cruz-Vega DE (2015) Liver fibrosis and mechanisms of the protective action of medicinal plants targeting inflammation and the immune response. Int J Inflam 2015:e943497. https://doi. org/10.1155/2015/943497

2. Chan ES, Montesinos MC, Fernandez P, Desai A, Delano DL, Yee H, Reiss AB, Pillinger MH, Chen JF, Schwarzschild MA, Friedman SL, Cronstein BN (2006) Adenosine A2A receptors play a role in the pathogenesis of hepatic cirrhosis. Br J Pharmacol 148:1144-1155. https://doi.org/10.1038/sj.bjp.0706812

3. Dranoff JA, Feld JJ, Lavoie EG, Fausther M (2014) How does coffee prevent liver fibrosis? Biological plausibility for recent 
epidemiological observations. Hepatology 60:464-467. https:// doi.org/10.1002/hep. 27032

4. Gressner OA, Lahme B, Siluschek M, Gressner AM (2009) Identification of paraxanthine as the most potent caffeinederived inhibitor of connective tissue growth factor expression in parenchymal cells. Liver Int 29:886-897. https://doi.org/10.111 1/j.1478-3231.2009.01987.x

5. Liu F, Wang X, Wu G, Chen L, Hu P, Ren H, Hu H (2015) Coffee consumption decreases risks for hepatic fibrosis and cirrhosis: a meta-analysis. PLoS One 10:e0142457. https://doi.org/10.1371/ journal.pone. 0142457

6. Molloy JW, Calcagno CJ, Williams CD, Jones FJ, Torres DM, Harrison SA (2012) Association of coffee and caffeine consumption with fatty liver disease, nonalcoholic steatohepatitis, and degree of hepatic fibrosis. Hepatology 55:429-436. https://doi. org/10.1002/hep.24731

7. Mod AA, Feld JJ, Park Y, Kleiner DE, Everhart JE, Liang TJ, Hoofnagle JH (2010) Increased caffeine consumption is associated with reduced hepatic fibrosis. Hepatology 51:201-209. https://doi. org/10.1002/hep.23279

8. Salomone F, Galvano F, Volti GL (2017) Molecular bases underlying the hepatoprotective effects of coffee. Nutrients 9:e85. https:// doi.org/10.3390/nu9010085

9. Gawlik-Dziki U, Świeca M, Dzik D, Kowalska I, Pecio Ł, Durak A, Sęczyk Ł (2014) Lipoxygenase inhibitors and antioxidants from green coffee-mechanism of action in the light of potential bioaccessibility. Food Res Int 61:48-55. https://doi.org/10.1016/j. foodres.2014.05.002

10. Ji LL, Jiang P, Lu B, Sheng Y, Wang X, Wang Z (2013) Chlorogenic acid, a dietary polyphenol, protects acetaminophen-induced liver injury and its mechanism. J Nutr Biochem 24:1911-1919. https://doi.org/10.1016/j.jnutbio.2013.05.007

11. Shi H, Dong L, Jiang J, Zhao J, Zhao G, Dang X, Lu X, Jia M (2013) Chlorogenic acid reduces liver inflammation and fibrosis through inhibition of toll-like receptor 4 signaling pathway. Toxicology 303:107-114. https://doi.org/10.1016/j.tox.2012.10.025

12. Shi H, Dong L, Bai Y, Zhao J, Zhang Y, Zhang L (2009) Chlorogenic acid against carbon tetrachloride-induced liver fibrosis in rats. Eur J Pharmacol 623:119-124. https://doi.org/10.1016/j. ejphar.2009.09.026

13. Kobayashi H, Tanaka Y, Asagiri K, Asakawa T, Tanikawa K, Kage M, Yagi M (2010) The antioxidant effect of green tea catechin ameliorates experimental liver injury. Phytomedicine 17:197-202. https://doi.org/10.1016/j.phymed.2009.12.006

14. Janevski M, Antona KN, Sullivan-Gunn MJ, McGlynn MA, Lewandowski PA (2011) The effect of cocoa supplementation on hepatic steatosis, reactive oxygen species and LFABP in a rat model of NASH. Comp Hepatol 10:e10. https://doi. org/10.1186/1476-5926-10-10

15. Żyżelewicz D, Zakłos-Szyda M, Juśkiewicz J, Bojczuk M, Oracz J, Budryn G, Miśkiewicz K, Krysiak W, Zduńczyk Z. Jurgoński A (2016) Cocoa bean (Theobroma cacao L.) phenolic extracts as PTP1B inhibitors, hepatic HepG2 and pancreatic $\beta$-TC3 cell cytoprotective agents and their influence on oxidative stress in rats. Food Res Int 89:946-957. https://doi.org/10.1016/j.foodr es.2016.01.009

16. Budryn G, Zaczyńska D, Oracz J (2016) Effect of addition of free and nanoencapsulated chlorogenic acids on aroma of different food products. LWT Food Sci Technol 73:197-204. https://doi. org/10.1016/j.lwt.2016.06.019
17. Budryn G, Zaczyńska D, Rachwał-Rosiak D (2016) Changes of free and nanoencapsulated hydroxycinnamic acids from green coffee added to different food products during processing and in vitro enzymatic digestion. Food Res Int 89:1004-1014. https ://doi.org/10.1016/j.foodres.2015.12.011

18. Sant'Anna LB, Sant'Anna N, Parolini O (2011) Application of computer-assisted image analysis for identifying and quantifying liver fibrosis in an experimental model. J Comput Interdiscip Sci 2:139-148. https://doi.org/10.6062/jcis.2011.02.02.0041

19. Cho JJ, Hocher B, Herbst H, Jia JD, Ruehl M, Hahn EG, Riecken EO, Schuppan D (2000) An oral endothelin-A receptor antagonist blocks-collagen-synthesis and deposition in advanced rat liver fibrosis. Gastroenterology 118:1169-1178. https://doi. org/10.1016/S0016-5085(00)70370-2

20. Schuppan D, Strobel D, Hahn EG (1998) Hepatic fibrosis: therapeutic strategies. Digestion 59:385-390

21. Schuppan D, Afdhal NH (2008) Liver cirrhosis. Lancet 371:838851. https://doi.org/10.1016/S0140-6736(08)60383-9

22. Lukivskaya O, Patsenker E, Lis R, Buko VU (2008) Inhibition of inducible nitric oxide synthase activity prevents liver recovery in rat thioacetamide-induced fibrosis reversal. Eur J Clin Investig 38:317-325. https://doi.org/10.1111/j.1365-2362.2008.01941.x

23. Seki E, Schwabe RF (2015) Hepatic inflammation and fibrosis: functional links and key pathways. Hepatology 61:1066-1079. https://doi.org/10.1002/hep.27332

24. Van Dijk F, Olinga P, Poelstra K, Beljaars L (2015) Targeted therapies in liver fibrosis: combining the best parts of platelet-derived growth factor BB and interferon gamma. Front Med 2:1-13. https ://doi.org/10.3389/fmed.2015.00072

25. Luo XY, Takahara T, Kawai K, Fujino M, Sugiyama T, Tsuneyama K, Tsukada K, Nakae S, Zhong L, Li XK (2013) IFN- $\gamma$ deficiency attenuates hepatic inflammation and fibrosis in a steatohepatitis model induced by a methionine- and choline-deficient high-fat diet. Am J Physiol Gastrointest Liver Physiol 305:G891G899. https://doi.org/10.1152/ajpgi.00193.2013

26. Arauz J, Moreno MG, Cortes-Reynosa P, Salazar EP, Muriel P (2013) Coffee attenuates fibrosis by decreasing the expression of TGF- $\beta$ and CTGF in a murine model of liver damage. J Appl Toxicol 33:970-979. https://doi.org/10.1002/jat.2788

27. Shi H, Shi A, Dong L, Lu X, Wang Y, Zhao J. Dai F, Guo X (2016) Chlorogenic acid protects against liver fibrosis in vivo and in vitro through inhibition of oxidative stress. Clin Nutr 35:13661373. https://doi.org/10.1016/j.clnu.2016.03.002

28. Hsu SJ, Lee FY, Wang SS, Hsin IF, Lin TY, Huang HC, Chang CC. Chuang CL, Ho HL, Lin HC, Lee SD (2015) Caffeine ameliorates hemodynamic derangements and portosystemic collaterals in cirrhotic rats. Hepatology 61:1672-1684. https://doi.org/10.1002/ hep. 27679

29. Budryn G, Zakłos-Szyda M, Zaczyńska D, Żyżelewicz D, Grzelczyk J, Zduńczyk Z, Juśkiewicz J (2017) Green and roasted coffee extracts as antioxidants in $\beta \mathrm{TC} 3$ cells with induced oxidative stress and lipid accumulation inhibitors in 3T3L1 cells, and their bioactivity in rats fed high fat diet. Eur Food Res Technol 243:1323-1334. https://doi.org/10.1007/s00217-017-2843-0

30. Salomone F, Li Volti G, Vitaglione P, Morisco F, Fogliano V, Zappalà A, Palmigiano A, Garozzo D, Caporaso N, D'Argenio G, Galvano F (2014) Coffee enhances the expression of chaperones and antioxidant proteins in rats with nonalcoholic fatty liver disease. Transl Res 163:593-602. https://doi.org/10.1016/j. trs1.2013.12.001 